\title{
The Analysis of Information Crowdsourcing Cloud for Disaster Management: Case Studies of Taiwan Morakot Typhoon
}

\author{
Sheng-Ming Wang ${ }^{1}$ \\ Department of Interaction Design, National Taipei Universty of Technology \\ No. 1, Zhong-Xiao East Road, Section 3, Taipei, TAIWAN \\ E-mail: ryan5885@mail.ntut.edu.tw
}

With the development of social networks, the mechanism of crowdsourcing is not limited to commercial application. In the event of disaster, information disseminated through social networks, and the mechanism of crowdsourcing thus is established. However, it is worth discussing whether the accuracy of the disaster information through the virtual community can be referred to the government agencies. This research extracted and analyzed the data from "the most serious disaster information in the major disaster information social network" of 2009 Taiwan Morakot typhoon. It also discussed the relevance and trust of crowdsourcing disaster information through extracting, comparing and analyzing. The result indicated that the disaster information extracted from the developed disaster information virtual community of the crowdsourcing mechanism was significant in its trust and relevance. It is recommended that the Federal Emergency Management Agency not only needs to pay attention on the information management of professional disaster prevention and protection along with the development and application of decision support system, bus also establishes virtual communities to manage professional social networks in peacetime. Thus, it can improve the efficiency on dealing with contingency or emergency through the diversification of information channels during calamity. The future studies of this research will focus on organizing the extracted database, introducing a complete evaluation model for trust analysis of disaster crowdsourcing information.

Keywords: Disaster Information, Crowdsourcing, Virtual Community, Relevance, Trust

International Symposium on Grids and Clouds (ISGC) 2014

Academia Sinica, Taipei, Taiwan

23-28 March, 201

1

Speaker 


\section{Introduction}

The idea or crowdsourcing majorly described a renovated commercial model, which developed new forms of organizations, through internet, Web 2.0 and the development of digital technology (Howe 2006). Huberman et al. (Huberman et al. 2009) indicated that individuals or organizations may take advantage of collective originality and ability to solve problems or complete jobs through the operation of internet and virtual community. On the contrary, the crowds in the virtual community participating in problem solving and job completing. The problem solving and production mode of such disseminate framework provided industry an innovative labor structure (Huberman et al. 2009). Problems are opened to unknown problem solvers in virtual community. And then, the crowds in virtual community upload collective solutions through individuals cluster with group interaction. The development of diversified online communities and the mechanism of crowdsourcing, which becomes more interactive and convenient, is promoted with the generalization of internet and the development of online community platform. Moreover, under the trend development of Web 2.0 and Service-Oriented Architecture (SOA) (Skopik et al. 2011), the mechanism of crowdsourcing not only provides the members of online community necessary information and solutions, but also collects group intelligence to carry out innovative projects (Heer et al. 2010). Besides, the mechanism of crowdsourcing has been developed from the commercial origin to academic and entertaining related applications. It has been extended to extract disaster information (Chu et al. 2011; Gao et al. 2011; Goodchild et al. 2010). At the same time, it establishes necessary methods and mechanisms to collect information immediately by integrating special information and disaster management (Bareiss et al. 2011; Goodchild et al. 2010; Savelyev et al. 2011; Starbird et al. 2011). The August 2009 Taiwan Morakot Typhoon was taken as an example in this study, and how to extract the disaster information immediately through crowdsourcing mechanism had also been discussed.

\section{Morakot Typhoon Outline and Literature Review}

This study will first outline the websites, which compile disaster information through crowdsourcing mechanism during Morakot typhoon. Second, we will discuss the concept and mechanism of crowdsourcing through scientific and technical literatures. Third, we will discuss the application of crowdsourcing in disaster information management. Last, the relevance and trust of virtual community will be discussed.

\subsection{Morakot Typhoon Disaster Information Crowdsourcing Platforms}

Morakot Typhoon brought a huge amount of rain which caused a serious disaster on August 7th and 8th 2009 throughout many regions of Taiwan. The internet users inside and outside the impact areas set up different platforms to collect information through the mechanism of crowdsourcing and to establish disaster information exchangeable and supportable efficacy. These disaster information exchangeable platforms not only indemnified government agencies insufficient capability to deal with contingency and emergency at the critical moment during typhoon, but also provided related information as a reference of disaster emergency for government agencies, non-governmental rescue teams and volunteer organizations to actively support the victims in disaster areas. Moreover, they also provide alternative ways for victims to be in contact with their relatives outside of the disaster areas. 
This research sorted disaster information platforms which provided crowdsourcing mechanism through nongovernmental autonomous development in Taiwan during Morakot Typhoon, they are as follow:

1. Morakot Typhoon disaster information map: The users and online volunteers of a website named Billypan employed Google Map and Google Earth to provide immediate disaster information. Its major character was to incorporate spatial location and to use maps which explicitly indicated the location of different events and disasters. The website could both provide spatial location for rescuers and assist decision makers in dealing with contingency and emergency. Figure 1 is extracted schematic diagrams while we participated in disaster report during the disaster. Currently, the website has been closed.

2. Morakot Typhoon disaster support website: It was set up by the users of a website named xdite. This website posted up information on support needed around Taiwan, in the mean time; it allowed supporters to post up information of the available materials. Currently, the website has been closed.

3. Morakot Typhoon victims report website: It was set up by Plurk user, Gene, on Plurk. The website reported immediate related disaster information spontaneously through keyword search engine. Currently, the website still can be accessed and has become Typhoon information Plurk. Another example to report disaster and make immediate response through Plurk website is that Su Huan Chih, Tainan county magistrate, and the county government officers extracted local disaster information and immediate response from Plurk users, then, actively provide assistance to local victims. That was the only case that local government made disaster management decision through online community at that time.

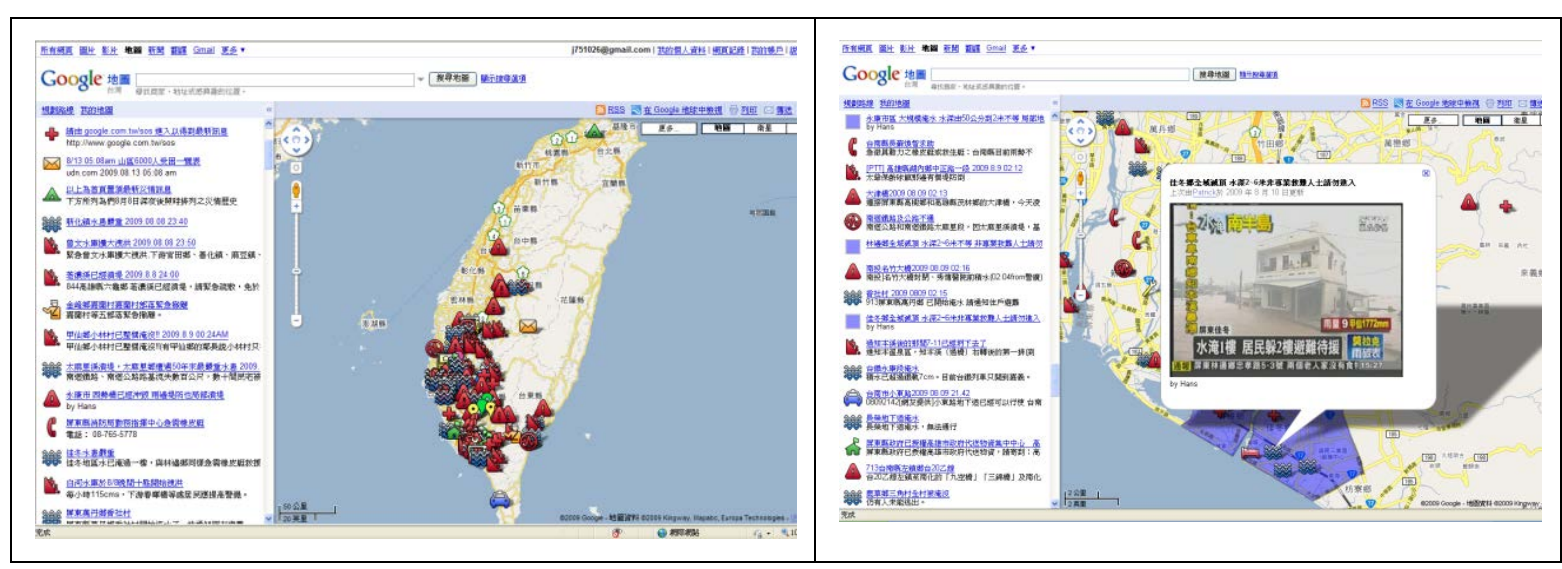

Figure 1 "Morakot Typhoon disaster information map" extracted schematic diagrams of

disaster information

4. PTT Emergency: "Morakot Typhoon disaster information report and exchange board" is provided by "PTT folk rescue team" and Taiwan online users to discuss on the very popular PTT BBS discussion board. It disseminated and updated disaster information swiftly. The website team had been dismissed on 22 August 2009, and the website had stopped updating related information on 15 September 2009. The website still retains all the extracted disaster information through crowdsourcing mechanism at present. It also provides information like: sharing folk volunteer experienced and linking video recording. 
5. Table for typhoon disaster information (http:// http://typhoon.oooo.tw/): This website is set up by TP4.Rickz[mouse]oooo.tw, which is in charge of website setup and management, and Shadow@3WA.tw is responsible for website design and maintenance. It has started operation since 1 am August 9, 2009. Through easy interactive interface and database, it provides columns of disaster serial number, time, country and city, detail address, ways to contact, disaster occurred, materials and help needed, and the most updated situation for people to upload. In comparison with other websites, which only provide disaster information and pictures, this website provides a column with "the most updated situation" for online users or users participating in information uploading with time series. These updated information can be renewed persistently by the original uploader, other users can also make immediate responses and update the information. Detail address and ways to contact have been retained in the online platform. On the one hand, it is convenient for rescue teams to find the correct locations; on the other hand, the situation can be confirmed through cell phone. One thousand eight hundred ninety eight disaster data were collected by 12am August 11th 2009; nevertheless, in a total of 4,495 data were collected by 12 am August 16th 2009. The website also provides information on follow-up restoration persistently. Basically, the crowdsourcing mechanism of this website is very simple; as a consequence, it collects rather large amounts of data.

6. Google Morakot Typhoon rescue webpage: This webpage is set up by Google. It compiles typhoon disaster and flood disaster related information through web link. Morakot Post-Disaster Reconstruction Council, Executive Yuan, updated news, video on Youtube and the related nongovernmental and governmental websites are linked. The satellite image of Kaohsiung and Pintung disaster areas from KML to Google Earth can be downloaded. The disaster maps are cited directly from the aforementioned "Morakot Typhoon disaster information map" by Billypan and its volunteers. Something particular about this website is that it provides a search engine to search Morakot related information and data and is still operating.

7. Taiwan flood and Morakot disaster network: It was an account built up by Association of Digital Culture Taiwan (ADCT) on Twitter. The website currently owned by Usaviah Disaster Prevention (http:// http://www.adct.org.tw/?project=usaviah). It emphasizes that you might be the next victim on facing disaster no matter which country you are from. Usaviah (a language from Bunun Tribe, means Jade Mountain) Disaster Prevention hopes to contribute to disaster information dissemination and disaster information system research as a citizen of global village. They welcome online users to join and help out translation as volunteers.

In considering the quality of each platform, "Morakot Typhoon disaster information map" and "Table for typhoon disaster information" were extracted in this study and the database were assessed for disaster information trust and relevance.

\subsection{Crowdsourcing, virtual community and disaster management}

"Crowdsourcing" majorly describes an innovated commercial behavior model (Howe 2006). The concept is through simple, available along with easy access interface and platform to create a different from traditional way, which outsourced work to other agents, of business. Instead, they outsource to members of community organization through the mechanism of online community to accomplish the job within a limited time. For example: iStockphoto was a website for a group of graphic designers to share pictures for free; nevertheless, it created an online trading platform for amateur photographers. However, the images provided are no longer 
limited to professionals. Freelancer, amateur photographer, student, engineer...etc can provide their professional works either free or paid through iStockphoto platform. Another model simply develops through online sharing platform, like: Digg, Flicker, YouTube, and Wikipedia to share diversified digital works. It not only reduces the cost of digital business, but also improves the convenience of sharing and application through the operation of crowdsourcing mechanism. Besides, crowdsourcing also provides with systematic decentralization. It keeps except to the interaction among same trades, also builds up a virtual community, which is a social network of individuals who interact through social media, may pass on and share knowledge and information with participants for common interest (Ebner et al. 2009). Users can raise questions on the opened platforms and solve problems together. At the same time, businessman may get more innovative ideas to improve their efficacy in the future through crowdsourcing.

Though, to integrate the operation of virtual community and crowdsourcing mechanism can innovate businessmen's ideas and operation models, they have to confront the problems raised from virtual community. Work quality cannot be controlled, which leads to loss or reduce productivity, due to realization problem from the providers. Besides, sharing numerous and unfiltered digital information on the platforms, users are easy to get lost and cause difficulties in application (Huberman et al. 2009). Related research also discuss trust in virtual communities and its effect on consumers' purchase intention ( $\mathrm{Lu}$ et al. 2010), and the impact on crowdsourcing is to the awareness of users and productivity (Huberman et al. 2009). From the above researches, although the crowdsourcing mechanism may create innovative and convenient advantages, its trust and relevance also need to be assessed and evaluated.

There are four main stages for disaster management: preparedness, mitigation, response and recovery. According to the categorization of Federal Emergency Management Agency (FEMA), the occurrence of disaster, one is natural disaster (like: earthquake, typhoon, flood) and the other is man-made disaster (like: terrorist attack, nuclear power event, chemical disaster). However, no matter natural or man-made disaster, related information, like: prevention, forewarning, early detection, disaster analysis, people and competent authority notification, mobile rescue, damage evaluation, post-disaster recovery...etc, needs to be collected and handled (Hristidis et al. 2010). Besides, timeliness and accuracy are most important factors in making disaster management decision. The abovementioned related information was collected by government agencies in traditional disaster management. With the development of Web 2.0 related technology as well as the rise of online media and social network, to integrate users' spontaneous organizations and strength through the concept of virtual community and to actively provide disaster information during disaster, i.e. disaster information crowdsourcing mechanism, are getting popular (Gao et al. 2011; Starbird et al. 2011). Moreover, with the development of cyberspace technology, volunteers link up cyberspace to establish disaster maps which provide more instinctive and efficient disaster information in supporting decision making (Bareiss et al. 2011; Goodchild et al. 2010; Savelyev et al. 2011).

\section{Research Method and Information Processing}

\subsection{Research and Analysis Model}

This study researched on the relevance of trust in crowdsourcing. Many references have been studies to understand the relevance of crowdsourcing, virtual community, and trust. The anticipation of this study is to apply the trust of crowdsourcing and virtual community to disaster information community. With the growing disaster events globally, many countries have developed post-disaster management system, which integrates the data from different sources and types as well as provides accurate and timely trustworthy data. However, in the absence of verification and local problems, the trust of information provided by virtual 
community often is neglected. Thus, this study aimed to discuss and bring in trust in crowdsourcing. The following is the extracted related research model in this study to alter the crowdsourcing trust model in cost study. The data extracted were from "Morakot Typhoon disaster information map" and "Table for typhoon disaster information". In considering the content of data and the assessable feature, the assess models from Lu et al. (Lu et al. 2010) and $\mathrm{Lu}$ and Yang(Lu et al. 2011) were taken as references to draw up this research model as shown in figure 2.

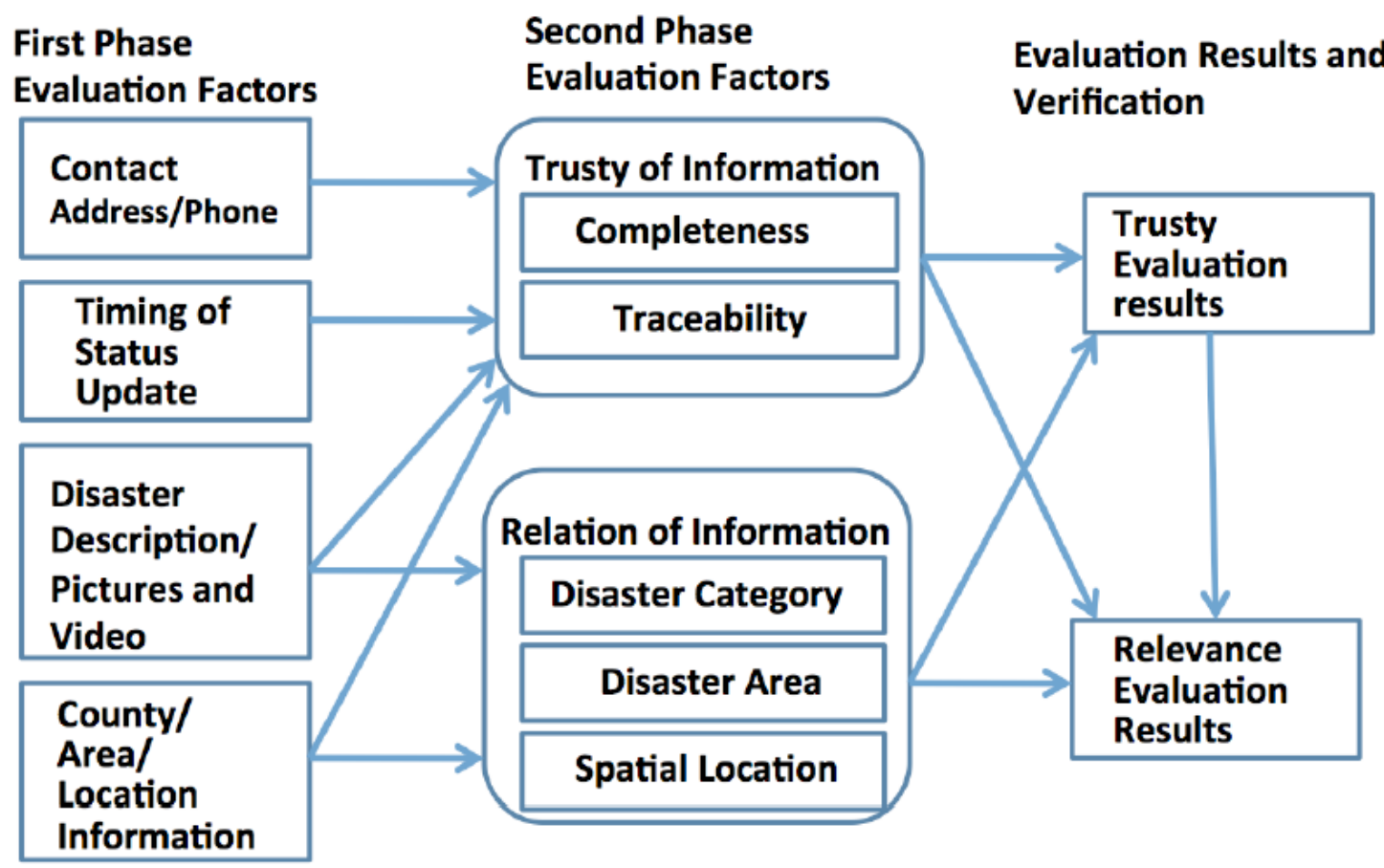

Figure 2 The research model of this study

There are three stages of assessment, assessment factors were designed in each stage. Assessment factors of first stage considered if disaster information, include: detail address/contact number, update time series, disaster description/ graph and video, and country, village location was provided. The former four factors were used to analyze trust assessment and the latter two factors were used to analyze its relevance. The assessment factor of trust in stage two was the integrity of extracted crowdsourcing information, and then assessed its traceability through comparison. As for relevance analysis, to assure the type of disaster, disaster area mentioned in disaster information and whether provided appropriate spatial location. On the third stage of assessment, this study aimed at cross comparison and analysis on trust and relevance to the result of assessment, assured the integrity of the result, and concluded the relevance of trust from extracted Morakot Typhoon disaster information through crowdsourcing. This study applied descriptive statistics to work out the synergy proportion of three stages. The method described in Lu and Yang(Lu et al. 2011) will be apply to factors and assessment analysis in the future.

\subsection{Extraction and disposition of crowdsourcing disaster information}

There are two sources of empirical research in this study. One was from "Morakot Typhoon disaster information map" platform, which started from 12 am August 8th, 2009 to 12 am August 11th 1009, in a total of 992 disaster information. The other one was extracted from “Table for typhoon disaster information”, which started from 12 am August 9th, 2009 to 12 am August 11th 2009, in a total of 1,898 disaster information. Related data were extracted from 
September to December 2009 in succession. "Morakot Typhoon disaster information map" platform had stopped its operation, it would be more difficult to verify its data. "Table for typhoon disaster information" platform is still operating at the moment. Related data can be linked to (http:// http://typhoon.oooo.tw/) for verification.

Figure 1 showed the extracted picture integrating disaster report, spatial location and graph/video link from "Morakot Typhoon disaster information map" platform. Figure 3 (left) showed an overlapping satellite map from "Morakot Typhoon disaster information map"; figure 3 (right) showed disaster map with different signs.

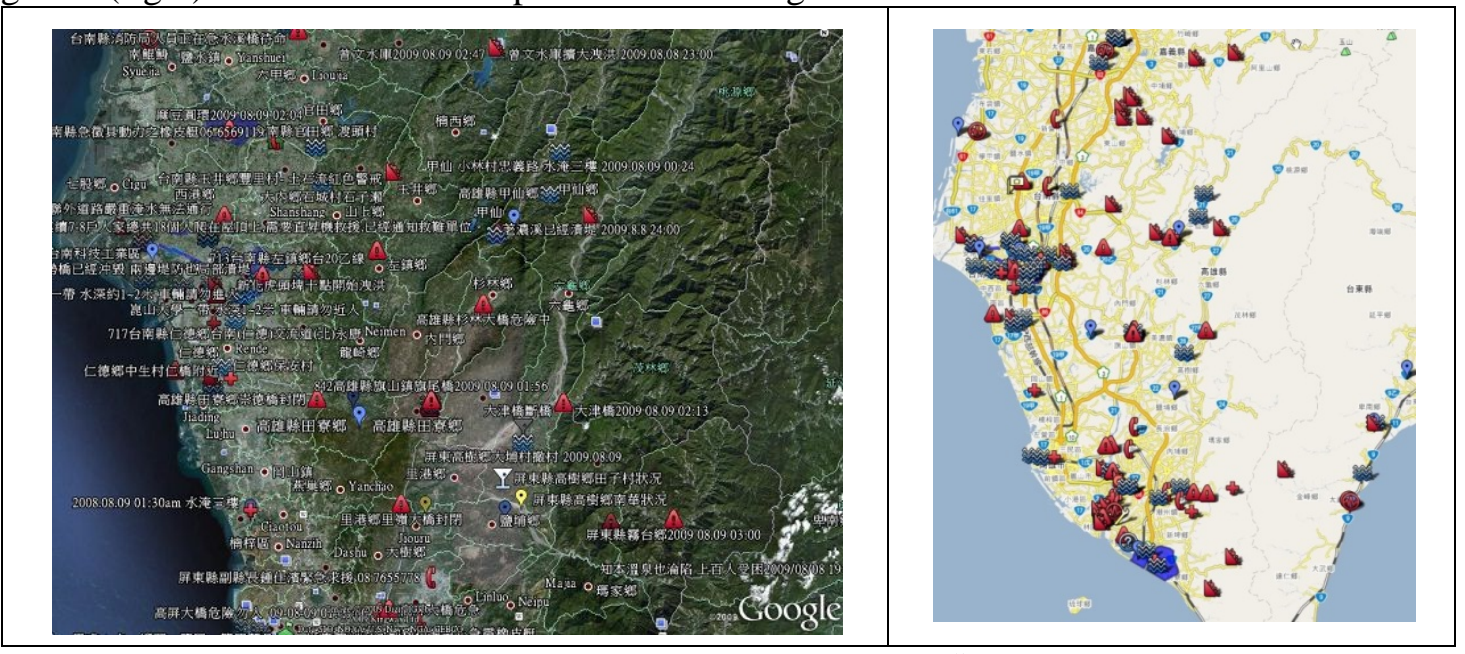

Figure 3 Extracted map from the disaster information of "Morakot Typhoon disaster information map" platform

The major content of "Morakot Typhoon disaster information map" was the record of unmarked spatial location in Google Map, media link (including link of graph, image and report), and description of disaster condition. The aforementioned information did not compile all the data into a table. Thus, these data should be manually sorted, like: number, time, country and city, type of disaster, media link, description of disaster, and updated condition, into a database for further analysis. In the extracted 992 data, 680 data did not show the uploaded time, only 312 data showed time series. There were 8 data uploaded on August 8th 2009, 303 data uploaded on August 9th 2009, and 1 data uploaded on August 10th 2009. In considering consistency, 303 data with time series uploaded on August 9th 2009 were extracted for further analysis in this research.

The other extracted disaster information was from "Table of typhoon disaster information" platform. A table that includes: Serial Number, Time, County and City Location, Detail Adress, Contact Information, Disaster Situation, Materials and Help Request, and Situatio Update, had been extracted for further analysis. Judging from the series number, it might have some errors in the beginning due to the skipped over numbers. According to the statistic of this research, there were 333 data uploaded on August 9th 2009, 532 data were uploaded on August 10th 2009, and 1033 data were uploaded on August 11th 2009. Basically, 1,898 disaster information was applicable. Nevertheless, considering consistent with the disaster information extracted from "Morakot Typhoon disaster information map", 333 data were extracted from "Table of typhoon disaster information" platform on August 9th 2009 in this research. The content of these data are then been further processed manually by using coding system for statistic analysis.

\section{Emprical Analysis Results and Discussions}

\subsection{Statistic Analysis of crowdsourcing disaster information}


There were 306 data extracted from "Morakot Typhoon disaster information map" and 333 data were extracted from "Table of typhoon disaster information". Figure 4 showed time series analysis of uploaded disaster information on the second day, which was August 9th 2009, while Morakot Typhoon happened. In accordance with principle of disaster management, emergency shall responses within 72 hours. Within this critical moment, sufficient disaster information is demanded to support decision making. Morakot brought huge amount of rain, it made landfall on August 7th 2009 at Hua-Lian, and passed over Taoyuan on August 8th 2009. Though, it did not stay long in Taiwan, but the storm caused a serious disaster. Figure 4 showed time series analysis from uploaded disaster information crowdsourcing network on August 9th, 2009. According to the figure, the number of disaster events had increased since two platforms started operation at $12 \mathrm{am}$ and reached to the first peak until 3-5 am. These events should happen the day before and was uploaded after the opening of the platforms. It leveled off between 11am and $1 \mathrm{pm}$. At 15-17 o'clock, the amount of disaster information on "Morakot Typhoon disaster information map" platform increased from trough. The amount of disaster information on “Table of typhoon disaster information” platform kept increasing. During 20-22 o'clock at night, the amount of disaster information increased on both platforms and reached to the peaks, which represented the disaster happened on August 9th 2009. The result of time series analysis provided an estimation of network flow for developing crowdsourcing disaster information collection in the future and a reference for web server flow management. These data could also provide rescue units to understand the increasing disaster events and allocate appropriate resource providing.

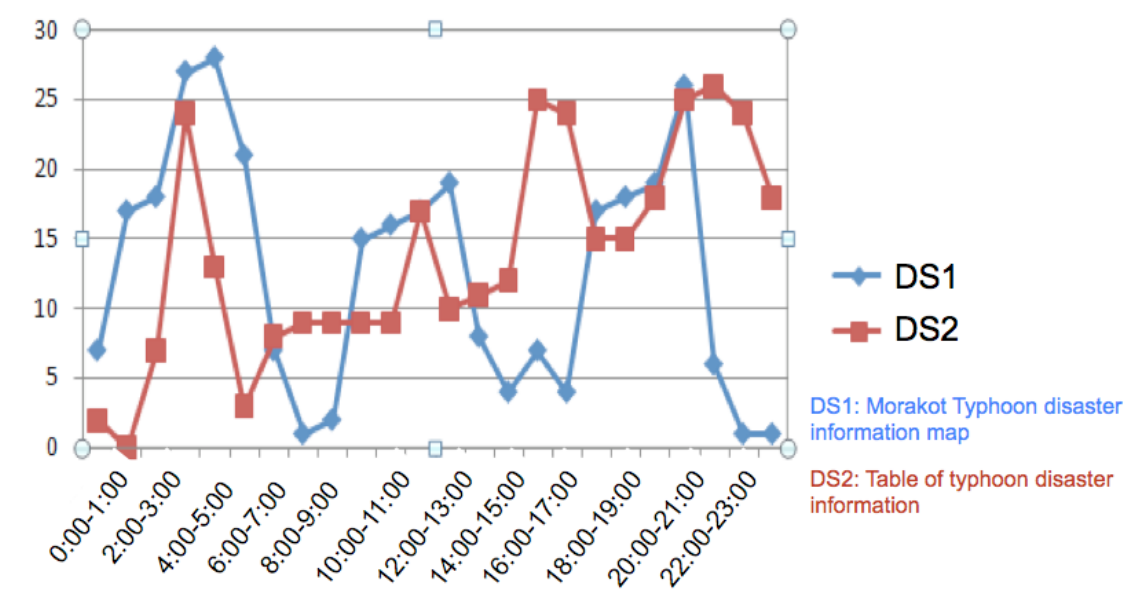

Figure 4 Time series analysis from uploaded disaster information crowdsourcing network on August 9th, 2009 


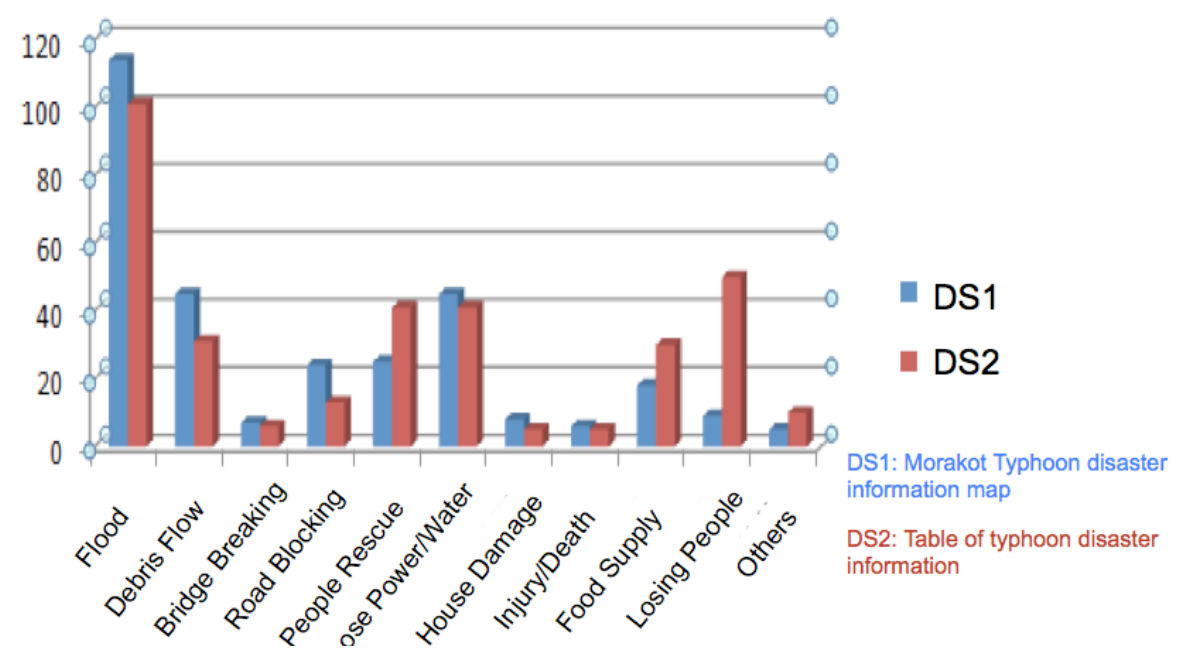

Figure 5 Comparison of classification from crowdsourcing disaster information networks of Morakot Typhoon on August 9th 2009

In the critical moment of emergency, the most important information for decision making is the classification of disaster information. Figure 5 showed the classification from two crowdsourcing disaster information networks. The major disaster was flood in both platforms. It conformed to the flood caused by Morakot Typhoon in Yu-Lin county, Tai-Nan county and Ping-Tung county.

Analyzing the patterns of overall information presented, "Morakot Typhoon disaster information map" provided information with a combination of Google spatial location; however, "Table of typhoon disaster information" provided information with the name of village and city. These help a lot in understanding the distribution of disasters. It was reasonable that water and electricity cut, rescue worker, and backup food were needed along with flood, while analyzing the database. Mudslide and rockslide mostly happened in Chia-Yi county and Kaohsiung county. It was proved accurate in comparison with the distribution of disaster afterwards. "Table of typhoon disaster information” was found a large number in searching missing people, which was account for $15 \%$ of the database. On the contrary, "Morakot Typhoon disaster information map” uploaded spatial location through graphical interface, little information in searching missing people has been found. Compared to "Morakot Typhoon disaster information map" platform, which needed to cope with searching and positioning in spatial location, the "Table of typhoon disaster information” platform adopted the pattern to fill in the table directly was much easier to upload names of village and city rather than spatial location for online users. As a consequence, more data for searching missing people on "Table of typhoon disaster information" platform were found. To exam and evaluate in response to the emergency in the critical moment, looking for missing people could alleviate the impact. It was suggested that a column for missing people searching shall be established in disaster information crowdsourcing operation mechanism to meet people's expectation in the future.

\subsection{Relevance and trust analysis of crowdsourcing disaster information}

The relevance and trust of crowdsourcing disaster information in this study was in accordance with the research model in Figure 2. The first stage of relevance analysis was to evaluate whether factors of disaster description, graph/video, and location of village and city included. As for the first stage of trust analysis was to evaluate whether factors of detail address/contact number, time series update condition, disaster description, graph/video, and location of village and city included. The assessment results were indicated in Figure 6. 


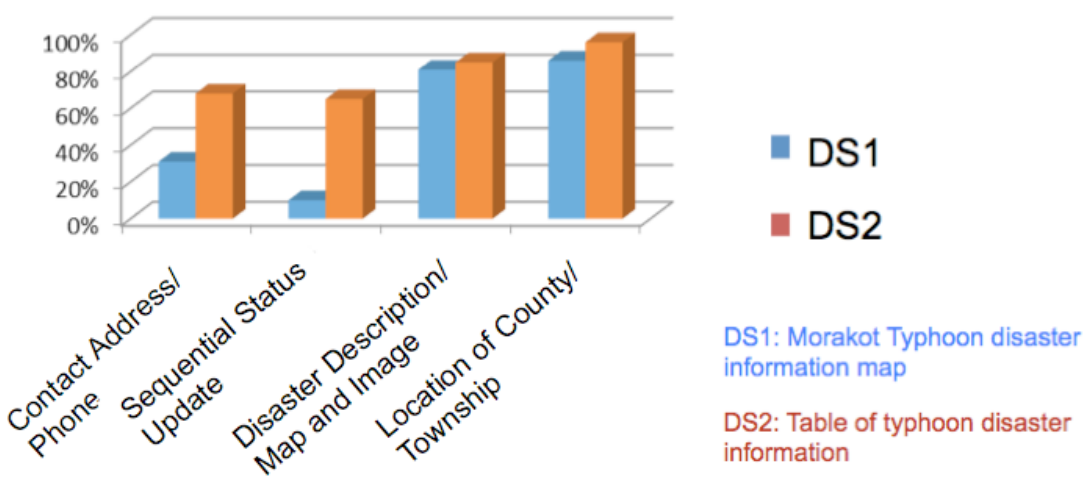

Figure 6 Assessment results of first stage relevance and trust analysis of crowdsourcing disaster information

The relevance of disaster information was intensive related with location, disaster description or illustration through graph/ video. From figure 6, two factors in relevance analysis on both platforms were both reached to $80 \%$. Thus, the information extracted from crowdsourcing disaster information and the real condition happened were relevant. Except from the aforementioned two factors, detail address/contact number and time series update condition were included in trust analysis. "Morakot Typhoon disaster information map" platform was found only $31 \%$ and $10 \%$ provided individually in Figure 6 . We assumed that it must have direct connection with the initial design of operative interface. It couldn't provide a convenient time series update mechanism, due to the introduction of database management mechanism. Users clicked on the interface to upload the location of disaster, but they would not upload the address any more. On the other hand, the design of "Table of typhoon disaster information" platform was established on mechanism of online database, which guided users to fill in two assessment factors information. It showed active facet of disaster information providers, if the detail address/contact phone number was provided in the trust analysis. If the time series update condition was provided, which meant such information had been paid attention persistently, and the trust was relatively higher.

The second stage of relevance analysis was to evaluate the indicated disaster types, disaster area, and spatial location in crowdsourcing disaster information and the integrity and traceability were assessed in the second stage of trust analysis. The assessment results were indicated in Figure 7.

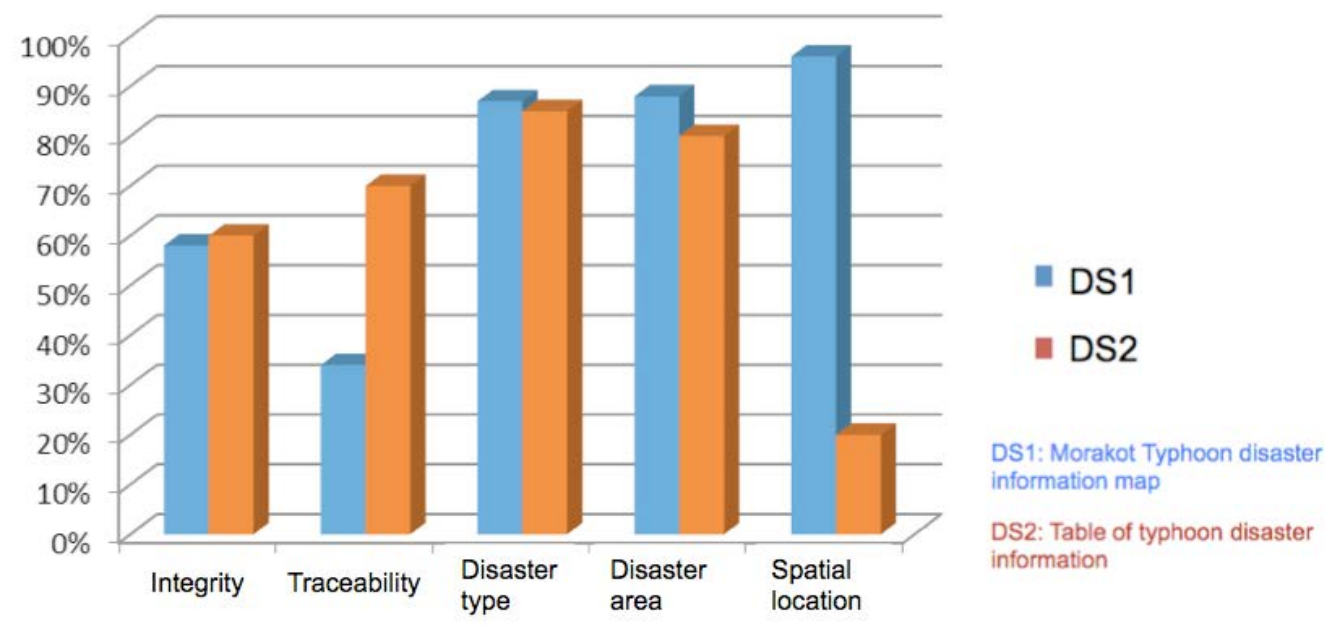


Figure 7 Assessment results of second stage relevance and trust analysis of crowdsourcing disaster information

Figure 7 indicated that the disaster type, disaster area and spatial location in relevance analysis, except for the relevance in "Table of typhoon disaster information" spatial location was only $20 \%$, other factors showed more than $80 \%$ of relevance. The manifestation of three factors in crowdsourcing disaster information through "Morakot Typhoon disaster information map" platform was better than through "Table of typhoon disaster information" platform. The users could link disaster information and spatial location through graphical interface; hence the manifestation of spatial location was better.

Two platforms showed no differences in integrity, but "Table of typhoon disaster information" platform was twice as much as "Morakot Typhoon disaster information map" platform in traceability on the second stage of trust assessment. It was because "Table of typhoon disaster information” platform provided updated information with time series, the latest disaster information and response could be easily tracked through search mechanism. Comparatively, "Morakot Typhoon disaster information map" platform majorly provided descriptive information, only if allocates with keyword and label in the process of pretreatment, will it be easier to do follow-ups.

Overall aforementioned analysis, the results indicated that the disaster information extracted from the disaster information crowdsourcing mechanism through "Morakot Typhoon disaster information map" platform and "Table of typhoon disaster information" platform is more significant in its relevance. However, it showed different extent in trust. The extracted information through "Morakot Typhoon disaster information map" platform provided instinctive graphical interface, so the manifestation of relevance is more significant. The result corresponded with the ideas raised by Bareiss et al. and Goodchild et al. (Bareiss et al. 2011; Goodchild et al. 2010). Due to the uncomplicated online database interface, the integrity and traceability showed better results in "Table of typhoon disaster information" platform. On the other hand, it provided a column, which could update disaster information time series, to increase the significance of disaster information crowdsourcing in its trust. The result accorded with the proposed issue, which suggested upgrading and tracking disaster information in network community persistently (Chu et al. 2011; Ebner et al. 2009; Lu et al. 2011).

\section{Conclusions and Future Studies}

The empirical research on the extracted disaster information crowdsourcing mechanism from "Morakot Typhoon disaster information map" platform and "Table of typhoon disaster information" platform during Morakot typhoon in this study indicated that the relevance of disaster and trust of extracted disaster information through crowdsourcing disaster information mechanism are significant. The integrated information shows immediate, uncomplicated and workable features in the application of disaster management through this mechanism; moreover, the victims can receive timely support with the immediate response to the disaster information. It is recommended that government integrate crowdsourcing mechanism through virtual communities to collect and extract disaster information in making emergency rescue decision during process of disaster management at the critical moment. In developing the platform of disaster through disaster information crowdsourcing mechanism, the "Morakot Typhoon disaster information map" platform with graphical interface and "Table of typhoon disaster information" platform with online database shall be integrated to provide disaster time series update mechanism for improving its relevance and trust.

The future studies of this research will focus on organizing the extracted disaster information, establishing complete database, introducing more quantitative evaluation models in accordance with the collected and extracted crowdsourcing disaster information and proposing a meticulous analysis in its trust. Furthermore, the most challenge for hazard mitigation is the 
ability of real-time data collection \& in-time analyses \& thus quick offer of mitigation decision. There have been substantial advances. Along with supercomputing \& HPC, in hazard mitigation, utilizing newly emerged non-expensive advanced digital infrastructure like in-memory data base, GPU and coprocessor computing,...etc are becoming available. Thus, further discussion about recent changes in hazard mitigation tech advance will also be provided in the future studies.

\section{Acknowledgement}

This study was supported by the grants from the Ministry of Science and Technology, Taiwan under of the porject of MOST 102-2410-H-027-014- and NSC100-2621-M- 143- 001

\section{References}

[1] Bareiss, R., Griss, M., Rosenberg, S., and Zhang, Y. "Semantic Geotagging: A Location-Based Hypermedia Approach to Creating Situational Awareness," in: MobiCASE 2011 : The 3rd International ICST Conference on Mobile Computing, Applications, and Services, Los Angeles, CA, 2011.

[2] Chu, E., Chen, Y., Liu, J., and Zao, J. "Strategies for crowdsourcing for disaster situation information," WIT Transactions on the Built Environment) 2011.

[3] Ebner, W., Leimeister, J. M., and Krcmar, H. "Community engineering for innovations: the ideas competition as a method to nurture a virtual community for innovations," R\&d Management (39:4) 2009, pp 342-356.

[4] Gao, H., Barbier, G., and Goolsby, R. "Harnessing the crowdsourcing power of social media for disaster relief," Intelligent Systems, IEEE (26:3) 2011, pp 10-14.

[5] Goodchild, M. F., and Glennon, J. A. "Crowdsourcing geographic information for disaster response: a research frontier," International Journal of Digital Earth (3:3) 2010, pp 231-241.

[6] Heer, J., and Bostock, M. "Crowdsourcing graphical perception: using mechanical turk to assess visualization design," Proceedings of the 28th international conference on Human factors in computing systems, ACM, Atlanta, GA, 2010, pp. 203-212.

[7] Howe, J. "The rise of crowdsourcing," Wired magazine (14:6) 2006, pp 1-4.

[8] Hristidis, V., Chen, S. C., Li, T., Luis, S., and Deng, Y. "Survey of data management and analysis in disaster situations," Journal of Systems and Software (83:10) 2010, pp 1701-1714.

[9] Huberman, B. A., Romero, D. M., and Wu, F. "Crowdsourcing, attention and productivity," Journal of Information Science (35:6) 2009, pp 758-765.

[10] Lu, Y., and Yang, D. "Information exchange in virtual communities under extreme disaster conditions," Decision Support Systems (50:2) 2011, pp 529-538.

[11] Lu, Y., Zhao, L., and Wang, B. "From virtual community members to C2C e-commerce buyers: Trust in virtual communities and its effect on consumers' purchase intention," Electronic Commerce Research and Applications (9:4) 2010, pp 346-360.

[12] Savelyev, A., Xu, S., Janowicz, K., Mülligann, C., Thatcher, J., and Luo, W. "Volunteered geographic services: developing a linked data driven location-based service," SSO '11 Proceedings of the 1st ACM SIGSPATIAL International Workshop on Spatial Semantics and Ontologies, ACM, Chicago, IL, 2011, pp. 25-31. 
[13] Skopik, F., Schall, D., Psaier, H., Treiber, M., and Dustdar, S. "Towards Social Crowd Environments Using Service-Oriented Architectures," it-Information Technology (53:3) 2011, pp 108-116.

[14] Starbird, K., and Palen, L. "Voluntweeters: Self-organizing by digital volunteers in times of crisis," CHI '11 Proceedings of the 2011 annual conference on Human factors in computing systems, ACM, Vancouver, BC, 2011, pp. 1071-1080.

[15] Yang, Y. F., Yeh, H. C., and Wong, W. K. "The influence of social interaction on meaning construction in a virtual community," British Journal of Educational Technology (41:2) 2010, pp 287-306. 